\title{
Clobazam is a Better Option for Intermittent Prophylaxis of Febrile Convulsion
}

Shahed lqbal ${ }^{*}$

Monir Ullah'

Razia Sultana ${ }^{2}$

Mahmood Ahmed Chowdhury ${ }^{3}$

'Department of Pediatrics

Chattagram Maa-O-Shishu Hospital Medical College Chittagong, Bangladesh.

${ }^{2}$ Department of Pathology

Chattagram Maa-O-Shishu Hospital Medical College Chittagong, Bangladesh.

${ }^{3}$ Institute of Child Health

Chattagram Maa-O-Shishu Hospital Medical College Chittagong, Bangladesh.

*Correspondence to:

Dr. Shahed lqbal Assistant Professor

Department of Pediatrics

Chattagram Maa-O-Shishu Hospital Medical College

Chittagong, Bangladesh

Mobile: +8801713162228

E-mail: dr.sim72@yahoo.com

\begin{abstract}
Aims: To compare safety and efficacy of diazepam and clobazam. Objectives: This study was undertaken to compare the effectiveness of intermittent clobazam versus diazepam therapy in preventing the recurrence of febrile convulsion and assess adverse effects of each drug. Methods: This is a hospital based randomized controlled trial was performed on neurologically normal children with the history of simple febrile convulsion and normal electroencephalogram without any evidence of acute central nervous system infection, done in Chattagram Maa Shishu-O-General Hospital/CMSOGH between November' 12 to April'13. A total of 37 patients were randomly prescribed with oral clobazam and diazepam was given in 35 patients when they developed a febrile disease. All the patients were monitored regarding developing seizure and adverse effects of the drugs. All patients were followed for 12 months. Results: It was observed that 243 attacks of fever occurred during the period, including 116 attacks in the clobazam group and 127 episodes in the diazepam group. Recurrence of convulsion occurred in $2(1.7 \%)$ subjects in the clobazam group, and in $4(3.1 \%)$ cases in the diazepam group. Twenty cases $(54 \%)$ in the diazepam group and $5(14.2 \%)$ cases in the clobazam group developed drowsiness and sedation during the follow-up period. Conclusion: Intermittent clobazam therapy has better advantage over diazepam with similar efficacy but significantly lower adverse effects such as drowsiness and sedation.
\end{abstract}

Key words: Febrile convulsion; Seizures; Clobazam.

\section{INTRODUCTION}

Febrile seizures are seizures that occur between the age of 6 and 60 monhs with a temperature of $38 \mathrm{C}$ or higher, that are not the result of central nervous system infection or any metabolic imbalance, and that occur in the absence of a history of prior afebrile seizure ${ }^{1}$.

Most cases occur between 5 months and 5 years of age with peak age of 18 months ${ }^{2-4}$. Genetic factors are important in the etiology of febrile seizures ${ }^{5}$. Children of parents who who had febrile seizures have a risk 4 times that of the general population and siblings of probands have a risk of 3.5 times that of general population. It accounts for approximately $25 \%$ of childhood status epilepticus ${ }^{6}$. Febrile convulsions frequently recur, with a recurrence rate of $50 \%$ when the first attack occurs before one year of age. In general, one third of infants will develop a second attack following subsequent febrile illness; half of the latter group will experience a third febrile seizure as well ${ }^{7-8}$. Febrile convulsion recurs 3 or more times in $10 \%$ of cases ${ }^{6}$.

More than one half of recurrences are experienced during the first year and over $90 \%$ develop within two years, following the first attack, with the higher risk within the first 6 to 12 months.

The likelihood for recurrence is greater among infants who convulse at temperatures below $40 \mathrm{C}^{3}$. The risk of recurrence is about $30 \%$ for simple febrile convulsion and over $50 \%$ for complex febrile convulsion ${ }^{8}$. 
The overall prognosis for febrile seizures is excellent ${ }^{9}$. The intellectual \& behavioral outcome of febrile seizure Is excellent ${ }^{10}$. The risk of developing epilepsy in children who have had febrile seizures is increased compared to that of general population. The risk is $2 \%$ at 5 yaers, $4.5 \%$ at 10 years, $5.5 \%$ at 15 years and $7 \%$ at 25 years ${ }^{11}$.

Treatment of Febrile convulsion consists of controlling the convulsions with anticonvulsants in dosages analogous to those recommended for the treatment of status epilepticus, reduction of the body temperature via conductive or evaporative cooling of the patient and treatment of the acute infection responsible for the fever ${ }^{3}$.

The recurrence rate of $30-50 \%$ and family anxiety rationalize the prophylaxis ${ }^{8}$. Benzodiazepine agents through oral, rectal or sublingual route can be administered as intermittent prophylaxis $^{12-14}$. Diazepam is the most common agent used for this purpose but it has side effects such as drowsiness, ataxia and sedation ${ }^{13-14}$. Clobazam is the first and only benzodiazepine in the management of epilepsy. It is used as effective antiepileptic agent in adults and children ${ }^{2,7-8,12}$. The side effects of clobazam are similar to other benzodiazepines, but with lower severity. In the study, the authors compared the effectiveness and adverse effects of clobazam vs diazepam in the prevention of recurrence of febrile convulsion.

\section{MATERIALS \& METHODS}

This prospective, randomized, superiority, intention to treat method controlled trial study was conducted in children aged 660 month with one or more episodes of simple febrile convulsion, how were referred to the Bahrami Children Hospital, Tehran, Iran, from March 2006 until one year.

The study was approved by the ethics committee of the university. Children with simple febrile seizure whose parents had severe anxiety (residing far from medical center, having multiple caregivers and poor accessibility to medical personnel) are included in study.

Exclusion criteria included the presence of neurological abnormalities, progressive neurological diseases, complex febrile convulsion, symptomatic seizures of other nature, seizures during a central nervous system infection and cases of simple febrile convulsion that had abnormal electroencephalogram.

Sample size was calculated with at least 18 patients in each group, considering alpha error of $5 \%$ power of $80 \%$ and effectiveness of $35 \%$ for diazepam, group and $1.7 \%$ for clobazam based on the results of reference no. $7^{12-13}$.

Patients were randomly assigned to receive oral diazepam 0.33 $\mathrm{mg} / \mathrm{kg}$ dose every $8 \mathrm{~h}$ for 2 days or oral clobazam for 2 days with the following dosage: $5 \mathrm{mg}$ daily in children $\leq 5 \mathrm{~kg} ; 5 \mathrm{mg}$, twice daily (BD) in children $6-10 \mathrm{~kg} ; 7.5 \mathrm{mg}$, BD in children $11-15 \mathrm{~kg}$; and $10 \mathrm{mg} \mathrm{BD}$ in children $>15 \mathrm{~kg}$. The medicines were administered only for the first $48 \mathrm{~h}$ of each febrile illness and stopped after $48 \mathrm{~h}$, irrespective of the persistence of fever. Using antipyretics and body sponge in addition for specific management of the disease, were in addition for specific management of the disease, were advise to both groups.
The children were visited every 3 month for 12 months. Outcome variables were occurrence of febrile convulsion and adverse effects of the drugs. On each visit, the frequency of febrile illness and adverse effects of the therapy were evaluated. Data were analyzed using chi-square and fisher-exact tests with significance level set at $<0.05$.

\section{RESULTS}

Thirty seven patients in diazepam group and 35 patients in the clobazam group completed the study. Of the total patients, 41 $(56.9 \%)$ were males and $31(43.1 \%)$ females. Mean age of the patients was 21 months (range 7-60 months) (Table 1)

During 12 months follow-up period, 243 episodes of fever occurred which included 116 (47.7\%) episodes in the clobazam group and $127(52.3 \%)$ episodes in diazepam group. Two patients $(1.7 \%)$ in the clobazam group and 4 patients $(3.1 \%)$ in diazepam group were in their febrile episodes. $(\mathrm{p}=0.474)$.

Table 1: Baseline demographic characteristics of trial group (clobazam vs diazepam)

$\begin{array}{lcr}\text { Characteristic } & \begin{array}{c}\text { Clobazam group } \\ \mathrm{n}=35\end{array} & \begin{array}{c}\text { Diazepam group } \\ \mathrm{n}=35\end{array} \\ \text { Mean age } & 21 \pm 3.1 & 21 \pm 5 \\ \text { Sex } & 19(54.28) & 22(59.45) \\ \text { Male } & 16(45.71) & 15(40.54) \\ \text { Female } & 116(47.73) & 127(52.26) \\ \text { Episode of fever } & 2(1.7) & 4(3.1) \\ \text { Episode of seizure } & & \end{array}$

Figures in parenthesis indicate percentage

Odds ratio of clobazam compared to diazepam with $95 \%$ confidence interval was $0.54(0.01-3)$ and number needed to treat was 71.43 .

\section{DISCUSSION}

For the prevention of recurrence of febrile convulsion benzodiazepine showed a unique role and efficacy ${ }^{3-4,6,8,13-14}$. Some studies have compared clobazam against placebo as prophylaxis for febrile convulsion and there are few studies comparing diazepam with clobazam in this regard ${ }^{4,12,15-16}$. Bajaj, in a double blind placebo-controlled study reported that recurrence of febrile convulsion was observed in 30\% patients in the clobazam group vs $83.3 \%$ in the placebo group. They concluded that clobazam is efficacious and well tolerated as intermittent prophylaxis of febrile convulsion and is superior to the use of intermittent antipyretics alone ${ }^{15}$.

Manresa performed a study on 50 children with febrile seizures and found that clobazam is an effective prophylaxis for febrile convulsion. Recurrence rate was $1.7 \%$ in the clobazam group and $22.9 \%$ in patients who received only antipyretic $(\mathrm{P}<0.0001)^{17}$.

Rose and coworkers evaluated the efficacy and safety of intermittent clobazam prophylaxis for febrile seizures in a prospective randomized double-blind placebo controlled trial and reported $1.7 \%$ recurrence of seizure in the clobazam group vs $12.5 \%$ in the placebo group $(\mathrm{p}=0.01)^{12}$. 
Gulati $\mathrm{S}$ in a randomized controlled trial compared efficacy of oral clobazam (75 cases) with oral diazepam (75 cases) for prophylaxis of febrile seizures. They reported a rate of febrile illness in $86.7 \%$ and $93.3 \%$ of patients in the diazepam and clobazam group respectively, during 3 years. The odds ratio of seizure recurrence was 2.3 in the diazepam group as compared to clobazam group ${ }^{16}$. This study is also consistent with their study.

Sunil barande believed that oral diazepam and clobazam are equally effective and safe in the in the prophylaxis of recurrence of febrile convulsion ${ }^{4}$. They found that oral clobazam is more effective in preventing febrile convulsion recurrence as compared to diazepam for this purpose is children with history of at least one episode of febrile convulsion ${ }^{4}$. The present study also showed that oral clobazam for the recurrence of febrile convulsion is comparable to that of oral diazepam.
However, adverse effects of clobazam were lower than diazepam. Sedation was more often in patients who received diazepam compared to clobazam.

Rose et al reported that ataxia due to clobazam was much lower than that of diazepam. ${ }^{12}$ Such finding did not show in the present study. Other side effects such as nausea and vomiting are not mentioned in present patients. Because due to better compliance and less adverse effects makes clobazam better option than diazepam for prophylaxis of febrile seizures.

\section{CONCLUSION}

Intermittent clobazam therapy has better advantage over diazepam with similar efficacy but significantly lower adverse effects such as drowsiness and sedation.

\section{DISCLOSURE}

All the authors declared no competing interest.

\section{REFERENCES}

1. Mikati MA. Febrile seizures in :Kliegman MR, Behrman RE, Schor NF, Nelson textbook of pediatrics. $19^{\text {th }}$ ed.Philadelphia: Saunders. 2011; 2017-2018.

2. Bajaj AS, Bajaj BK, Vinod P, Girish T. Intermittent clobazam in Febrile Seizures; An Indian experience. J Pediatr Neurol. 2005;3:19-23.

3. Karande S. Febrile Seizures: a review for family physicians. Indian J Med Sci. 2007;61:161-72.

4. Gupta S. Febrile seizures. An overview and use of clobazam as intermittent therapy. Pediatr Today. 2002;7:244-249.

5. Wallace SJ. Febrile seizures. In: Wallace SJ,Farrel K, eds. Epilepsy in children. London: A RNOLD;2004;123-130.

6. Shinner S. Febrile seizures. In: Swaiman Kf, Ashwal S, Ferriero DM,eds. Pediatric neurology principles \& practice. $4^{\text {th }}$ ed. Philadelphia: Mosby. 2006;1079-1082.

7. Fenichel CM. Clinical Pediatric Neurology: A sign and symptoms approach. $4^{\text {th }}$ ed. Philadelphia : Saunders. 2001;18-19.

8. Rose W, Kirubakaranc C, Scott JX. Intermittent clobazam therapy in Febrile Seizures. Indian J Pediatr.2005;72:31-33

9. KnudsenFU. Febrile seizure: Treatment \& prognosis. Epilepsia. 2000; 41:2-9.

10. Verity CM,Greenwood R, Golding J. Long term intellectual and behavioral outcomes of children with febrile convulsion. N ENG J MED. 1998; 338:1723-1728.

11. Annegers JF. Hauser WA, Shirts SB, Kurland LT. Factors prognostic of unprovoked seizure after febrile convulsions. N ENG J MED. 1987; 316:493-498.

12. Pavlidou E, Tzitiridou M, Panteliadis C. Effectiveness of intermittent diazepam prophylaxis in Febrile Seizures: longtime prospective controlled study. J Child Neurol.2006;21:1036-1040.

13. Verrotti A, Latini G, di Corcia G, Giannuzzi R, CSalladini C, Trotta D. Intermittent oral diazepam prophylaxis in febrile convulsions: its effectiveness for febrile Seizure recurrence . Eur J Pediatr Neurol.2004;8:131-134.

14. Akman CI. Febrile Seizures :the role of intermittent prophylaxis. J Pediatr Neurol.2005;3:1-3.

15. Manreza MLG,Gherpelli JLD, Machado HLR, Pedreire CCC, Diament A, Heise CO. Treatment of Febrile Seizures with intermittent clobazam. Arq Neuropsiquiatr. 2007;55:757-761

16. Gulati S, Saini D, Pandey RM, Kala v. Randomized controlled trial to compare efficacy of oral clobazam with oral diazepam for prophylaxis of. Febrile Seizures. Neuropediatrics.2006;37-13.

17. Sankar R. Paroxysmal disorders. In: Menkes JH, samat HB, Maria BL,eds. Child neurology. $7^{\text {th }}$ ed. Philadelphia: Lippincott William \& Wilkins. 2006;919-922. 